\title{
BMJ Rehabilitation impact indices and their Open independent predictors: a systematic review
}

\author{
Gerald Choon-Huat Koh, ${ }^{1}$ Cynthia Huijun Chen, ${ }^{1}$ Robert Petrella, ${ }^{2,3}$ \\ Amardeep Thind ${ }^{2}$
}

To cite: Koh GC-H, Chen $\mathrm{CH}$, Petrella $\mathrm{R}$, et al.

Rehabilitation impact indices and their independent predictors: a systematic review. BMJ Open 2013;3: e003483. doi:10.1136/ bmjopen-2013-003483

- Prepublication history and additional material for this paper is available online. To view these files please visit the journal online (http://dx.doi.org/10.1136/ bmjopen-2013-003483).

GCK and $\mathrm{CHC}$ contributed equally to this work.

Received 1 July 2013 Revised 13 August 2013 Accepted 15 August 2013

\footnotetext{
${ }^{1}$ Saw Swee Hock School of Public Health, National University of Singapore, National University Health System, Singapore, Singapore

2Department of Family Medicine, Schulich School of Medicine \& Dentistry, University of Western Ontario, London, Ontario, Canada

${ }^{3}$ Lawson Health Research Institute, London, Ontario, Canada
}

Correspondence to Dr Gerald C Koh; Gerald_Koh@nuhs.edu.sg

\section{ABSTRACT}

Objectives: To (1) identify all available rehabilitation impact indices (RIIs) based on their mathematical formula, (2) assess the evidence for independent predictors of each RII and (3) propose a nomenclature system to harmonise the names of Rlls.

Design: Systematic review.

Data sources: PubMed and references in primary articles.

Study selection: First, we identified all available RII through preliminary literature review. Then, various names of the same formula were used to identify studies, limited to articles in English and up to 31 December 2011, including case-control and cohort studies, and controlled interventional trials where RIls were outcome variable and matching or multivariate analysis was performed.

Results: The five RIls identified were (1) absolute functional gain (AFG)/absolute efficacy/total gain, (2) rehabilitation effectiveness (REs)/Montebello Rehabilitation Factor Score (MRFS)/relative functional gain (RFG), (3) rehabilitation efficiency (REy)/length of stay-efficiency (LOS-EFF)/efficiency, (4) relative functional efficiency (RFE)/MRFS efficiency and (5) revised MRFS (MRFS-R). REy/LOS-EFF/efficiency had the most number of supporting studies, followed by REs and AFG. Although evidence for different predictors of RIls varied according to the RII and study population, there is good evidence that older age, lower prerehabilitation functional status and cognitive impairment are predictive of poorer AFG, REs and REy. Conclusions: 5 Rlls have been developed in the past two decades as composite rehabilitation outcome measures controlling premorbid and prerehabilitation functional status, rate of functional improvement, each with varying levels of evidence for its predictors. To address the issue of multiple names for the same RII, a new nomenclature system is proposed to harmonise the names based on common mathematical formula and a first-named basis.

\section{INTRODUCTION}

Little is known about composite indices of rehabilitation outcomes and the effects of sociodemographic factors and comorbidities

\section{ARTICLE SUMMARY}

Strengths and limitations of this study

- Use of only one citation database for our literature search. Our literature search was limited to only articles in English due to the high cost of technical translations as well as the validity of how these rehabilitation impact indices (RIIs) were recorded.

- It is the first rehabilitation literature to methodically review all RIls available based on their formula for calculation. It proposes a nomenclature system to harmonise the names of RIls across the rehabilitation discipline based on a rational first-named basis.

- Evidence of independent predictors accessed in these RIls were applied over a wide range of medical conditions and study populations.

on these indices. Thus, there is a need to (1) identify and characterise robust rehabilitation impact indices (RIIs) that can be measured across sites and settings for comparative effectiveness research, and (2) determine the key predictors of these RIIs so that the former can be adjusted for meaningful evaluation across sites and settings.

Currently, many studies in rehabilitation use the final functional status as the outcome measure after adjusting for the participant's initial functional status. However, both were highly correlated resulting in most variation in multivariate analysis being accounted by initial functional status. ${ }^{1}$ Moreover, the final functional status does not consider speed of functional recovery or achievement of rehabilitation potential both of which are important in quality of care. ${ }^{2}{ }^{3}$ Researchers have devised several RIIs that account for baseline functional status. However, these RIIs have been given different names although they share the same mathematical formula, which is inconsistent and confusing. Moreover, the independent predictors of RIIs have never been systematically identified 
for the wide range of conditions requiring rehabilitation. Hence, we performed a systematic review to (1) identify all available RIIs and their synonyms, and categorise them according to mathematical formula, (2) identify and assess the evidence for independent predictors of each RII, and (3) propose a nomenclature system to harmonise the terminology of RIIs.

\section{METHODS}

We conducted this review according to the Preferred Reporting Items for Systematic Reviews and Meta-Analyses (PRISMA) statement for reporting systematic reviews. ${ }^{4}$

To achieve the first two aims of the study, we conducted the systematic review in two stages. The first stage was to identify all available RIIs and categorise them according to the same mathematical formula but under different names. For example, the difference between admission and discharge functional scores was termed as absolute function gain (AFG), absolute efficacy or total gain. The second stage was to use these different names and report their independent predictors. For example, we used the terms 'absolute function gain', 'absolute efficacy' and 'total gain' to identify all articles using difference between admission and discharge functional scores. RIIs are prospective as they require functional status to be measured across two time points. Hence, to determine the independent predictors of RIIs, we included case-control and cohort studies, and controlled interventional trials that had RIIs as outcomes, and excluded descriptive studies that did not examine factors associated with RIIs. We deemed factors as independent predictors if multivariate analysis was performed. In controlled trials, the intervention was considered a predictive factor.

Studies were identified from PubMed (until 31 December 2011) as the primary citation database to conduct our literature search and reviewed the articles referenced in these primary for secondary literature which may be eligible for our systematic review. Search terms were specific for each RII. For absolute functional gain, we used the search terms 'absolute function gain', 'absolute efficacy' and 'total gain'. For rehabilitation effectiveness (REs), we used the search terms 'rehabilitation effectiveness', 'Montebello Rehabilitation Factor score' and 'relative functional gain'. For rehabilitation efficiency (REy), we used the search terms 'rehabilitation efficiency', 'length-of-stay efficiency' and 'efficiency'. For relative functional efficiency (RFE), we used the search terms 'relative functional efficiency' and 'MRFS efficiency'.

We limited our search to articles in English as the cost of technical translations was beyond our budget. Of note, we did not limit any medical condition (eg, stroke) or study population (eg, elderly) as rehabilitation is a specialty defined by treatment and our primary aim was to study the properties of RIIs in the full range of study populations. The abstracts of all articles retrieved were first screened for use of RIIs, subsequently the full articles were retrieved if they satisfied the criteria described above. Details of the primary articles eligible for the systematic review were extracted and tabulated (see online supplementary tables S1-S3), and their statistically significant $(p<0.05)$ independent predictors were identified. Evidence for a factor as a predictor of an RII was deemed to be none if there was no supporting study, weak if there was only one supporting study, fair if there were two supporting studies, moderate if there were three supporting studies and good if there were four or more supporting studies. Similar systems of using number of supporting studies to weigh scientific evidence have been used by previous systematic reviews. ${ }^{56}$

We did not perform a meta-analysis of pooled data to generate the overall effect size for each predictor because of the small number of studies available for each predictor after stratification by study population, different functional measures were used across studies which limited pooling of estimates and important data were missing from primary articles which precluded pooling of estimates (eg, CIs). Lastly, we proposed a nomenclature system to harmonise the terminology of RIIs for future use on the basis that the name of the RII should (1) follow the name coined by the first author(s) to define it and (2) be logical and intuitive. This study was exempted from ethics review because it did not involve human participants.

\section{RESULTS}

From the first stage of our systematic review, we identified five RIIs used in rehabilitation literature. Figure 1 details the study selection process, including the five RIIs identified and their synonyms, the number of potentially relevant articles retrieved from PubMed, the number of full articles satisfying study eligibility criteria and the final number of articles accessed. For the remaining Results section, we will present mathematical formula for each RII, its synonyms and its independent predictors.

\section{Absolute functional gain/absolute efficacy/total gain}

AFG was first coined by Heruti $e t a l^{7}$ as the difference in functional measure score before and after rehabilitation. Mathematically, the formula (FIM, functional independence measure; DC, discharge; adm, admission) is as follows:

$$
\mathrm{AFG}=\mathrm{DC}(\mathrm{FIM})-\operatorname{adm}(\mathrm{FIM})
$$

Other authors have referred to AFG as absolute (FIM) efficacy or total (FIM) gain. ${ }^{7-13}$ After performing a systematic literature search using these names as search terms, we found seven studies which studied predictors for this RII. ${ }^{7-13}$ All these studies used FIM as the functional measure. The predictors of poorer AFG/absolute efficacy/total gain stratified by the study population are summarised in table 1 and details are found in online supplementary table S1. 


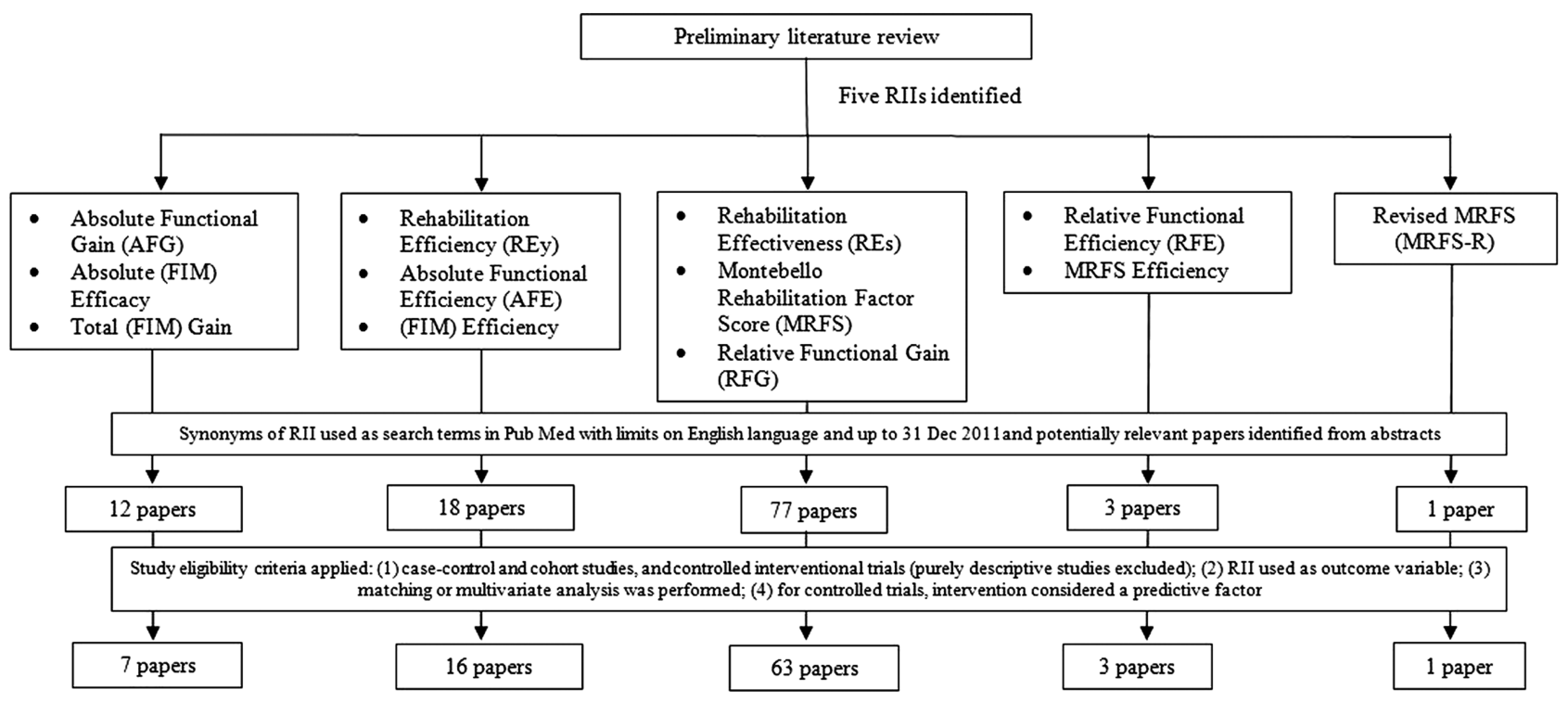

Figure 1 Study selection process for the five rehabilitation impact indices (RIls) identified.

From table 1, independent predictors of poorer AFG/ absolute efficacy/total gain are older age, ${ }^{11} 13$ lower prerehabilitation functional status, ${ }^{11}$ cognitive impairment, ${ }^{7}$ 9-11 non-treatment with thrombolysis ${ }^{13}$ and greater neurological impairment. ${ }^{13}$ The independent predictors were supported by stroke (2 studies), post-hip-fracture arthroplasty ( 2 studies) and the elderly (1 study).

\section{Rehabilitation effectiveness/Montebello Rehabilitation Factor Score/ \\ Relative functional gain}

REs was a concept first suggested by Heinemann et al. ${ }^{1}$ However, it was Shah et al who coined the term rehabilitation effectiveness later in $1990 .{ }^{14}$ Expressed as a percentage reflecting the proportion of potential improvement actually achieved during rehabilitation, it can be calculated using the formula (BI, Barthel index; DC, discharge; adm, admission; max, maximum possible score):

$$
\mathrm{REs}=\frac{\mathrm{DC}(\mathrm{BI} \text { or FIM })-\operatorname{adm}(\mathrm{BI} \text { or FIM })}{\operatorname{Max}(\mathrm{BI} \text { or FIM })-\operatorname{adm}(\mathrm{BI} \text { or FIM })} \times 100 \%
$$

REs are viewed to be superior to AFG/absolute efficacy/ total gain because the latter does not take into account the potential maximal functional improvement. For example, patient A improved his BI score from 20 to 60, whereas patient B improved his BI score from 60 to 100; although both patients improved by $40 \mathrm{BI}$ units, patient A has only reached $((60-20) /(100-20))=40 / 80=50 \%$ of his highest possible level of improvement, whereas patient $\mathrm{B}$ has reached his highest possible level of improvement $(100 \%)$ and is now independent.

REs were renamed by other authors as Montebello Rehabilitation Factor Score (MRFS) in 1994 and relative functional gain (RFG) in 2007. After performing a PubMed search, 16 studies were identified. ${ }^{1} 9^{14-26}$ The predictors of poorer REs/MRFS/RFG stratified by study population are summarised in table 2 and details are found in online supplementary table S2.

From table 2, independent predictors of poorer REs/ MRFS/RFG that have been reported are (1) older age, ${ }^{1} 14 \quad 152426$ (2) lower prerehabilitation functional

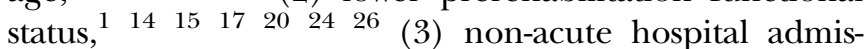
sions, $^{1}$ (4) cognitive impairment, ${ }^{7} \quad 9 \quad 16 \quad 182023 \quad 24 \quad 26$

Table 1 Summary of independent factors of poorer absolute functional gain (AFG), absolute efficacy or total gain from studies by study population*

\begin{tabular}{llll}
\hline $\begin{array}{l}\text { SI. } \\
\text { no. }\end{array}$ & $\begin{array}{l}\text { Independent factors of poorer AFG, } \\
\text { absolute efficacy or total gain }\end{array}$ & Stroke & $\begin{array}{l}\text { Post-hip-fracture } \\
\text { arthroplasty }\end{array}$ \\
\hline 1 & $\begin{array}{l}\text { Older age } \\
\text { Lower prerehabilitation functional }\end{array}$ & 11 Elderly \\
2 & Status & 11 & - \\
& Cognitive impairment & 11 & - \\
3 & Prior stroke with motor impairment & - & 79 \\
4 & Non-treatment with thrombolysis & 13 & - \\
5 & Greater neurological impairment & 13 & - \\
6 & & - & - \\
\hline${ }^{*}$ Article reference numbers in cells. & &
\end{tabular}


Table 2 Summary of independent factors of poorer rehabilitation effectiveness (REs) or Montebello Rehabilitation Factor Score (MRFS) or relative functional gain (RFG) from studies by study population*

\begin{tabular}{|c|c|c|c|c|c|}
\hline $\begin{array}{l}\text { SI. } \\
\text { no. }\end{array}$ & $\begin{array}{l}\text { Independent factors of poorer } \\
\text { REs/MRFS/RFG }\end{array}$ & Stroke & $\begin{array}{l}\text { Post-hip-fracture } \\
\text { arthroplasty }\end{array}$ & Elderly & $\begin{array}{l}\text { Gait } \\
\text { disorders }\end{array}$ \\
\hline 1 & Older age & 114152426 & & - & - \\
\hline 2 & Lower prerehabilitation functional status & 11415172426 & 2022 & - & - \\
\hline 3 & Non-acute hospital admissions & 1 & - & - & - \\
\hline 4 & Cognitive impairment & 162426 & 791820 & 23 & - \\
\hline 5 & Urinary incontinence & 14 & - & 23 & - \\
\hline 6 & Myocardial infarction & 1 & - & - & - \\
\hline 7 & $\begin{array}{l}\text { Longer 'stroke onset to admission into } \\
\text { rehabilitation unit' time }\end{array}$ & 1426 & - & - & - \\
\hline 8 & $\begin{array}{l}\text { Longer 'admission to unit to start of } \\
\text { rehabilitation' time }\end{array}$ & 14 & - & - & - \\
\hline 9 & Poor adherence to clinical practice guidelines & 17 & - & - & - \\
\hline 10 & Orthogeriatric setting & - & 18 & - & - \\
\hline 11 & Subcortical vascular lesions & - & - & - & 21 \\
\hline 12 & Shorter length of stay & 26 & - & 23 & - \\
\hline 13 & Lower body mass index & - & - & 23 & - \\
\hline 14 & Unilateral spatial neglect & 25 & - & - & - \\
\hline 15 & Female gender & 26 & - & - & - \\
\hline 16 & Malay (vs Chinese) ethnicity & 26 & - & - & - \\
\hline 17 & Caregiver availability & 26 & - & - & - \\
\hline 18 & Ischaemic (vs haemorrhagic) stroke & 26 & - & - & - \\
\hline 19 & Users of psychotropic medication & 19 & - & - & - \\
\hline 20 & Territory of stroke & 17 & - & - & - \\
\hline 21 & Prior stroke & - & 22 & - & - \\
\hline
\end{tabular}

(5) urinary incontinence, ${ }^{14} 23$ (6) myocardial infarction ${ }^{1}$ (7) longer 'stroke onset to admission into rehabilitation unit' time ${ }^{14}{ }^{26}(8)$ longer 'admission to unit to start of rehabilitation' time, ${ }^{14}(9)$ poor adherence to clinical practice guidelines, ${ }^{17}$ (10) territory of stroke, ${ }^{17}$ (11) orthogeriatric setting (as compared with a two-step model of orthopaedic surgery followed by transfer to a geriatric rehabilitation facility), ${ }^{18}$ (12) users of psychology medications, ${ }^{19}$ (13) subcortical vascular lesions, ${ }^{21}$ (14) prior episode of stroke, ${ }^{22}$ (15) lower body mass index, ${ }^{23}$ (16) unilateral spatial neglect, ${ }^{25}$ (17) female gender, ${ }^{26}$ (18) Malay (vs Chinese) ethnicity, ${ }^{26}$ (19) caregiver availability, ${ }^{26}$ (20) infarct (vs haemorrhage) stroke $^{26}$ and (21) shorter length of stay (LOS). ${ }^{23} 26$ The independent predictors of REs/MRFS/RFG were supported by stroke (9 studies), post-hip-fracture arthroplasty (5 studies), elderly (1 study) and gait disorders (1 study). Overall, the evidence for older age (5 studies), lower prerehabilitation functional status (8 studies) and cognitive impairment (8 studies) as predictors of poorer REs/MRFS was strong.

\section{Rehabilitation efficiency/Length of stay-efficiency/ efficiency}

The concept of REy was also first suggested by Heinemann et $a l^{1}$ using the BI. Later, Shah et $a l^{14}$ renamed this concept to REy. It can be regarded as the average increase in the score of a functional assessment tool per day and is calculated using the following formula (where DC, discharge; adm, admission; date, date of functional assessment scoring):

$$
\mathrm{REy}=\frac{\mathrm{DC}(\mathrm{BI} \text { or FIM })-\operatorname{adm}(\mathrm{BI} \text { or FIM })}{\text { DateDC }- \text { dateadm }}
$$

REy is also known as LOS-efficiency (LOS-EFF) and FIM efficiency. Compared with REs/MRFS/RFG, there are many more studies which have used REy/LOS-EFF/efficiency with 63 studies examining predictors of this RII. ${ }^{1}$ 13-15 25-82 The predictors of poorer REy/LOS-EFF/ efficiency stratified by study population are summarised in table 3. The details of each study reporting REy/ LOS-EFF/efficiency are found in the online supplementary table S3. There were four pairs of studies which were potentially duplicate publications: $\left(\operatorname{Lin}^{43}\right.$ and Lin et $a l^{44}$; $\mathrm{Yu}$ and Richmond ${ }^{58}$ and Yu et $a \rho^{59}$; Vincent $e t a \ell^{64}$ and Vincent $e t a b^{67}$; Vincent $e t a b^{65}$ and Vincent $e t a b^{66}$; see online supplementary table S3). Only the last three pairs of studies reported independent predictors of REy/ LOS-EFF/efficiency (table 3). We chose to treat these studies as separate original studies as we could not be sure whether they were duplicate publications.

From table 3, the independent predictors of REy/ LOS-EFF/efficiency that have been reported are (1) admissions from sources other than home, ${ }^{1}$ (2) older

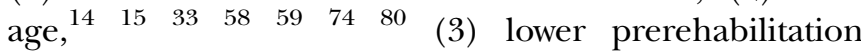


Table 3. Summary of independent factors of poorer rehabilitation efficiency (REy) or length-of-stay efficiency (LOS-EFF) or Functional Independence Measure (FIM) Efficiency by study population*

\begin{tabular}{|c|c|c|c|c|c|c|c|c|c|c|c|}
\hline S/No. & $\begin{array}{l}\text { Independent factors of poorer } \\
\text { REy/LOS Efficiency/FIM } \\
\text { Efficiency }\end{array}$ & Stroke & $\begin{array}{l}\text { Post hip } \\
\text { fracture } \\
\text { arthroplasty }\end{array}$ & Elderly & Heterogeneous & $\begin{array}{l}\text { Brain } \\
\text { tumor }\end{array}$ & $\begin{array}{l}\text { Brain } \\
\text { injury }\end{array}$ & $\begin{array}{l}\text { Spinal } \\
\text { cord } \\
\text { injury }\end{array}$ & Encephalitis & $\begin{array}{l}\text { Hemo } \\
\text { dialysis }\end{array}$ & $\begin{array}{l}\text { Knee } \\
\text { arthroplasty }\end{array}$ \\
\hline 1. & $\begin{array}{l}\text { Admissions from sources other than } \\
\text { home }\end{array}$ & 1 & - & - & - & - & - & - & - & - & - \\
\hline 2. & Older age & 141580 & 74 & $58+59+$ & - & - & - & 33 & - & - & - \\
\hline 3. & Lower pre-rehabilitation functional status & 141580 & 74 & $\begin{array}{l}4758 \dagger \\
59+\end{array}$ & - & - & - & - & - & - & - \\
\hline 4. & Ischemic (vs. hemorrhagic) stroke & 2628 & - & - & - & - & - & - & - & - & - \\
\hline 5. & Depression & 3442 & 54 & - & - & - & - & - & - & - & - \\
\hline 6. & Cognitive impairment & 26 & 754 & - & - & - & - & - & - & - & - \\
\hline 7. & Poorer balance & - & - & - & 30 & - & - & - & - & - & - \\
\hline 8. & $\begin{array}{l}\text { Heterotopic ossification on triple-phase } \\
\text { bone scan (vs. none) }\end{array}$ & - & - & - & - & - & 35 & - & - & - & - \\
\hline 9. & $\begin{array}{l}\text { Non-traumatic (vs. traumatic) spinal cord } \\
\text { injury }\end{array}$ & - & - & - & - & - & - & 38 & - & - & - \\
\hline 10. & $\begin{array}{l}\text { Encephalitis (vs. traumatic brain injury or } \\
\text { stroke) }\end{array}$ & - & - & - & - & - & - & - & 39 & - & - \\
\hline 11. & Longer length of stay & 1526 & - & - & - & - & - & - & - & - & - \\
\hline 12. & $\begin{array}{l}\text { Direct admission from emergency ward } \\
\text { (vs. indirect admission via general } \\
\text { medical ward) }\end{array}$ & 41 & - & - & - & - & - & - & - & - & - \\
\hline 13. & $\begin{array}{l}\text { Not receiving radiation therapy during } \\
\text { rehabilitation (vs. receiving) in brain } \\
\text { tumor patients }\end{array}$ & - & - & - & - & 45 & - & - & - & - & - \\
\hline 14. & $\begin{array}{l}\text { Recurrent (vs. first diagnosis) in brain } \\
\text { tumor patients }\end{array}$ & - & - & - & - & 45 & - & - & - & - & - \\
\hline 15. & Greater co-morbidity burden & - & 71 & 47 & - & - & - & - & - & - & - \\
\hline 16. & $\begin{array}{l}\text { Spinal stenosis-induced (vs. traumatic) } \\
\text { spinal cord injury }\end{array}$ & - & - & - & - & - & - & 49 & - & - & - \\
\hline 17. & Japan (vs. USA) & 50 & - & - & - & - & - & - & - & - & - \\
\hline 18. & Right hemispheric stroke & 51 & - & - & - & - & - & - & - & - & - \\
\hline 19. & Greater neurological impairment & 5179 & - & - & - & - & - & - & - & - & - \\
\hline 20. & Dialysis (vs. non-dialysis) patients & - & - & - & - & - & - & - & - & 53 & - \\
\hline 21. & $\begin{array}{l}\text { Program to reduce conflicts between } \\
\text { hemodialysis and therapy sessions }\end{array}$ & - & - & - & - & - & - & - & - & 56 & - \\
\hline 22. & Extremes of dependency & 5758 & - & - & - & - & 63 & - & - & - & - \\
\hline 23. & Discharge to nursing facility (vs. home) & 6061 & - & - & - & - & - & - & - & - & - \\
\hline \multirow[t]{2}{*}{24.} & Lower haemoglobin levels & - & - & - & - & - & - & - & - & - & 61 \\
\hline & & & & & & & & & & & Continued \\
\hline
\end{tabular}


Table 3. Continued

Independent factors of poorer

REy/LOS Efficiency/FIM

S/No. Efficiency

25. Longer 'stroke onset to admission into rehabilitation unit' time

26. Revision (vs. primary) total hip arthroplasty

27. Revision (vs. primary) total knee arthroplasty

28. Female gender

29. Aortic aneurysm repair induced (vs.

traumatic) spinal cord injury

30. Principal disability diagnosis (in order of decreasing FIM efficiency: traumatic

brain injury, stroke, spinal cord injury, amputations and pulmonary conditions)

31. Extremes of body-mass index

32. Primary (vs. co-morbid) debility diagnosis

33. Hispanic and black (vs. white) ethnicity

34. Lower staff to patient ratio

35. Neglect

36. Non-treatment with thrombolysis

37. Diabetes mellitus

38. Medications that predispose to falls

39. Malay (vs. Chinese) ethnicity

40. Caregiver availability (vs. no caregiver)

41. Higher pre-rehabilitation functional status

42. Peptic ulcer disease

* Paper reference numbers in cells

† The following pairs of reference numbers are potentially duplicate publications: [58 \& 59], [64 \& 67] and [65\& 66] 
functional status, ${ }^{14} 154758597480$ (4) non-haemorrhagic (vs haemorrhagic) stroke, ${ }^{26} 28$ (5) depression, ${ }^{34} 4254$ (6) cognitive impairment, ${ }^{7} 2654$ (7) poorer balance, ${ }^{30}$ (8) heterotopic ossification on triple-phase bone scan (vs none), ${ }^{35}$ (9) non-traumatic (vs traumatic) spinal cord injury, $^{38}$ (10) encephalitis (vs traumatic brain injury or stroke), ${ }^{39}$ (11) longer LOS, ${ }^{15} 26$ (12) direct admission from emergency ward (vs indirect admission via general medical ward), ${ }^{41}$ (13) not receiving radiation therapy during rehabilitation (vs receiving) in patients with brain tumour, ${ }^{45}$ (14) recurrent (vs first diagnosis) in patients with brain tumour, ${ }^{45}$ (15) greater comorbidity burden, ${ }^{47}{ }^{71}(16)$ spinal stenosis-induced (vs traumatic) spinal cord injury, ${ }^{49}$ (17) Japan (vs USA), ${ }^{50}$ (18) right hemispheric stroke, ${ }^{51} 79$ (19) greater neurological impairment, ${ }^{51}$ (20) patients undergoing dialysis (vs nondialysis), ${ }^{53}$ (21) programme to reduce conflicts between haemodialysis and therapy sessions, ${ }^{56}$ (22) extremes of dependency, 575863 (23) discharge to nursing facility (vs home), ${ }^{60} 61$ (24) lower haemoglobin levels, ${ }^{61}$ (25) longer 'stroke onset to admission into rehabilitation unit' time, ${ }^{26} 51{ }^{62}(26)$ revision (vs primary) total hip arthroplasty, ${ }^{64}$ (27) revision (vs primary) total knee arthroplasty, $^{65} 6672$ (28) female gender, ${ }^{65} 67$ (29) aortic aneurysm repair induced (vs traumatic) spinal cord injury, $^{68}$ (30) principal disability diagnosis (in order of decreasing FIM efficiency: traumatic brain injury, stroke, spinal cord injury, amputations and pulmonary conditions) ${ }^{70}$ (31) extremes of body mass index, ${ }^{71}$ (32) primary (vs comorbid) debility diagnosis, ${ }^{73}$ (33) Hispanic and African-American (vs white) ethnicity, ${ }^{74}$ (34) lower staff-to-patient ratio, ${ }^{76}$ (35) neglect, ${ }^{25} 79$ (36) nontreatment with thrombolysis, ${ }^{13}$ (37) diabetes mellitus, ${ }^{80}$ (38) medications that predispose to falls, ${ }^{80}$ (39) Malay (vs Chinese) ethnicity, ${ }^{26}$ (40) caregiver availability (vs no caregiver) ${ }^{26}$ (41) higher prerehabilitation functional status ${ }^{26}$ and (42) peptic ulcer disease. ${ }^{26}$ The medical conditions and study populations from which independent predictors of REy/LOS-EFF/efficiency were derived included strokes (21 studies), post-hip-fracture arthroplasty ( 7 studies), elderly (4 studies), heterogeneous (2 studies), brain tumour (1 study), brain injury (2 studies), spinal cord injury (4 studies), encephalitis (1 study), haemodialysis (2 studies) and knee arthroplasty (4 studies). Overall, the evidence for older age and lower prerehabilitation functional status as predictive of poorer REy/LOS-EFF/efficiency were good with seven (6 if 1 considers $\mathrm{Yu}$ and Richmond $^{58}$ and $\mathrm{Yu}$ et $a \bar{\rho}^{\tilde{9}^{9}}$ as duplicate publications) studies each reporting this association respectively with most of the studies based on stroke and elderly rehabilitation, a situation similar with REs/MRFS/ RFG. The evidence for cognitive impairment being predictive of poorer REy/LOS-EFF/efficiency was weaker when compared with REs/MRFS/RFG (3 vs 8 studies, respectively). Of note, unlike with REs/MRFS/RFG, the evidence for depression being predictive of poorer REy/ LOS-EFF/efficiency was stronger (none vs 3 studies, respectively).
Relative functional efficiency/MRFS efficiency

Heruti et $a l^{16}$ defined RFE in 2002 as REs/MRFS/RFG divided by LOS. In the same year, Zwecker et $a l^{83}$ used the term MRFS efficiency to describe the same formula. The formula for RFE/MRFS efficiency using FIM as the functional assessment tool (where DC, discharge; adm, admission; max, maximum possible score) is as follows:

$$
\begin{aligned}
\mathrm{RFE} & =\frac{\mathrm{DC}(\mathrm{BI} \text { or } \mathrm{FIM})-\operatorname{adm}(\mathrm{BI} \text { or } \mathrm{FIM})}{\operatorname{Max}(\mathrm{BI} \text { or } \mathrm{FIM})-\operatorname{adm}(\mathrm{BI} \text { or FIM })} \times \frac{1}{\mathrm{LOS}}=\frac{\mathrm{REs}}{\mathrm{LOS}} \\
& =\frac{\mathrm{AFG}}{(\operatorname{Max}(\mathrm{BI} \text { or } \mathrm{FIM})-\operatorname{adm}(\mathrm{BI} \text { or } \mathrm{FIM})) \times \mathrm{LOS}}
\end{aligned}
$$

Heruti et $a l^{16}$ demonstrated that the RFE/MRFS efficiency was higher in cognitively intact elderly participants $(n=79)$ compared to cognitively impaired elderly participants $(n=65)$ admitted into a geriatric rehabilitation unit but Zwecker et $a l^{83}$ found no associations between RFE/MRFS efficiency and cognitive function. Recently, Toglia et $a l^{84}$ found that the Montreal Cognitive Assessment (MoCA) was predictive of RFE/ MRFS efficiency in 72 patients with mild subacute stroke. To date, these are the only three articles so far that have used the RFE/MRFS efficiency index. Further studies are needed to increase the evidence base for predictors of this relatively new RII.

\section{Revised MRFS}

In 2007, Press et a $e^{85}$ proposed a new RII: the revised MRFS (MRFS-R). They proposed that the highest possible functional status should not be the maximum score of the functional assessment tool used but the premorbid functional score instead. For example, hypothetical patient A was quite functional with a premorbid functional score (premorbidFIM) of 120 before a fracture; after fracture repair, on admission to the rehabilitation department, patient A's admFIM score dropped to 60 . After rehabilitation, patient A's DCFIM rose to 80 . In this case, patient A's MRFS was 0.33, as follows:

$$
\begin{aligned}
\text { MRFS } & =\frac{\text { DCFIM }- \text { admFIM }}{\text { PremorbidFIM }- \text { admFIM }}=\frac{80-60}{120-60}=\frac{20}{60} \\
& =0.33
\end{aligned}
$$

Patient B who was much more dependent before suffering a hip fracture had premorbid functional score (premorbidFIM) of 80. Patient B's admFIM score dropped to 20 after hip fracture and after rehabilitation, patient B's DCFIM score rose to 40. In patient B's case, the MRFS score was also 0.33 :

$$
\begin{aligned}
\text { MRFS } & =\frac{\text { DCFIM }- \text { admFIM }}{\text { PremorbidFIM }- \text { admFIM }}=\frac{40-20}{80-20}=\frac{20}{60} \\
& =0.33
\end{aligned}
$$

As such, according to the MRFS formula, these two patients enjoyed an equal level of rehabilitation success. 
However, these two patients are different as patient B started with a poorer premorbid functional status than patient A. As such, Press et al proposed a revised MRFS which adjusts the MRFS to make it more relevant to clinical practice by changing the calculation from an absolute to a relative one and using the premorbid functional score as the highest possible functional status attainable, as follows:

$$
\begin{aligned}
\text { MRFS }-\mathrm{R} & =\frac{(\text { DCFIM }- \text { admFIM }) / \text { DCFIM }}{(\text { PremorbidFIM }- \text { admFIM }) / \text { premorbidFIM }} \\
& =\frac{\text { MRFS } / \text { DCFIM }}{\text { premorbidFIM }}
\end{aligned}
$$

Using this new index, patient A's MRFS-R would be 0.5 , as follows:

$$
\begin{aligned}
\text { MRFS }-\mathrm{R} & =\frac{(\text { DCFIM }- \text { admFIM }) / \text { DCFIM }}{(\text { PremorbidFIM }- \text { admFIM }) / \text { premorbidFIM }} \\
& =\frac{(80-60) / 80}{(120-60) / 120}=\frac{20 / 80}{60 / 120}=\frac{0.25}{0.5}=0.5
\end{aligned}
$$

Patient B's MRFS-R score would be higher at 0.67 , as follows:

$$
\begin{aligned}
\text { MRFS }-\mathrm{R} & =\frac{(\text { DCFIM }- \text { admFIM }) / \text { DCFIM }}{(\text { PremorbidFIM }- \text { admFIM }) / \text { premorbidFIM }} \\
& =\frac{(40-20) / 40}{(80-20) / 80}=\frac{20 / 40}{60 / 80}=\frac{0.5}{0.75}=0.67
\end{aligned}
$$

Press et al assert that patient B realised his/her rehabilitation potential more than patient $A$ and that the MRFS-R is a more useful way to quantify the differences. In the same article, Press et $a l^{85}$ compared the MRFS-R with MRFS and found that they were very highly correlated $(\mathrm{r}=0.99, \mathrm{p}<0.01)$. Nevertheless, in a linear regression model with MMSE, LOS and Severity Index of Cumulative Illness Rating Scale for Geriatrics as independent factors, they found the adjusted $R^{2}$ for MRFS-R was higher than with MRFS as the dependent variable (0.16 vs 0.12 ), suggesting that the MRFS-R accounted for more variance in the similar model than MRFS. As this is the first and currently only article that has used MRFS-R, more studies are needed to increase the evidence base for predictors of this new RII as well.

\section{DISCUSSION}

Increasingly complex RIIs have been developed in the past decade in response to the need to create composite summative measures that control for premorbid and prerehabilitation functional status, and rate of functional improvement. The current RIIs available in increasing complexity are: (1) AFG, (2) REs, (3) REy, (4) relative rehabilitation efficiency (RREy) and (5) relative rehabilitation effectiveness (RREs). On the basis of current literature, more studies have used REy than REs, and even fewer have used AFG, RREy or RREs. Thus, the number of known predictors is highest for REy than the other RIIs. Although the evidence varies, there is consistent evidence that older age, lower prerehabilitation functional status and cognitive impairment are predictive of poorer AFG, REs and REy, particularly in stroke and post-hip-fracture arthroplasty rehabilitation.

One of the possible reasons why few studies have used AFG as an RII could be that AFG does not take into account the potential maximal functional improvement like REs and RREs. Another reason could be that AFG does not consider the rate of functional improvement per unit time like REy and RREy. It is also worthwhile to note that although Heruti et als ${ }^{7}$ study found associations between cognitive impairment and REs, it did not find any such association with AFG, supporting the superiority of REs as an RII over AFG.

Most researchers use LOS for a hospital stay as the denominator for REy and RREy instead of the number of days between first and final functional assessment scoring. This is acceptable provided the functional scoring is performed close to the date of admission and discharge. However, if the first functional measurement was performed many days after admission or the last functional assessment was performed many days before date of discharge, REy and RREy may be spuriously high if LOS was used in the denominator. Hence, it may be more accurate to use the number of days between the date of first and last functional measurement as the denominator for REy instead of LOS, as conducted by Koh et $a l^{26}$ In fact, it was because Koh et al used time between first and last functional assessment in their study that they were able to demonstrate that LOS was an independent predictor of REy and not the result of statistical singularity arising from LOS being the denominator of REy.

Three RIIs use the variable 'maximal score attainable' (ie, max (BI or FIM)): REs, RREs and RREy. Some studies use the maximum score of the functional measurement tool (eg, 100 for BI and 126 for FIM), whereas other studies use the premorbid functional level of the patient (ie, prior to disabling event that necessitated rehabilitation, like stroke or hip fracture). The proponents for the latter argue that premorbid functional status is more appropriate because it is more meaningful to the patient and a person's function rarely improves beyond their premorbid functional status. However, there are disadvantages in using premorbid functional status as the 'maximal score attainable'. First, premorbid functional data are often not available as patients often present in acute settings already disabled from a stroke or hip fracture. Hence, premorbid functional data are often collected retrospectively from patient or caregiver and is vulnerable to recall bias. Second, studies have shown that persons can still improve their functional status months to years after their acute disabling event with rehabilitation, suggesting that one's premorbid functional status is not necessarily their maximal 
Table 4. Proposed harmonized nomenclature system for rehabilitation indices

\begin{tabular}{|c|c|c|c|}
\hline S/No. & Current Names & Formula* & Proposed Standard Name \\
\hline 1. & $\begin{aligned} & \text { Absolute Functional Gain } \\
& \text { (AFG) } \\
& \text { - Absolute (FIM) Efficacy } \\
& \text { - Total (FIM) Gain }\end{aligned}$ & $\mathrm{FIM}_{\mathrm{DC}}-\mathrm{FIM}_{\mathrm{Adm}}$ & Absolute Functional Gain (AFG) \\
\hline 2. & $\begin{array}{l}\text { Rehabilitation Effectiveness } \\
\text { (REs) } \\
\text { - Montebello Rehabilitation } \\
\text { Factor Score (MRFS) } \\
\text { Relative Functional Gain } \\
\text { (RFG) }\end{array}$ & 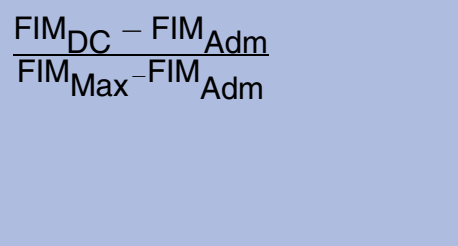 & $\begin{array}{l}\text { Rehabilitation Effectiveness (REs), prefixed by } \\
\text { functional measure used (e.g. FIM effectiveness, BI } \\
\text { effectiveness) }\end{array}$ \\
\hline 3. & $\begin{array}{l}\text { Rehabilitation Efficiency } \\
\text { (REy) } \\
\text { Length-of-Stay Efficiency } \\
\text { (LOS-EFF) } \\
\text { (FIM) Efficiency }\end{array}$ & $\frac{\mathrm{FIM}_{\mathrm{DC}}-\mathrm{FIM}_{\mathrm{Adm}}}{\text { LOS }}$ & $\begin{array}{l}\text { Rehabilitation Efficiency (REy), prefixed by functional } \\
\text { measure used (e.g. FIM efficiency, BI efficiency) }\end{array}$ \\
\hline 4. & $\begin{array}{l}\text { Relative Functional } \\
\text { Efficiency (RFE) } \\
\text { MRFS Efficiency }\end{array}$ & $\frac{\mathrm{FIM}_{\mathrm{DC}}-\mathrm{FIM}_{\mathrm{Adm}}}{\left(\mathrm{FIM}_{\mathrm{Max}}-\mathrm{FIM}_{\mathrm{Adm}}\right) X \mathrm{LOS}}$ & MRFS Efficiency \\
\hline 5. & Revised MRFS (MRFS-R) & $\frac{\left(\mathrm{FIM}_{\mathrm{DC}}-\mathrm{FIM}_{\mathrm{Adm}}\right) / \mathrm{FIM}_{\mathrm{DC}}}{\left(\mathrm{FIM}_{\mathrm{Max}}-\mathrm{FIM}_{\mathrm{Adm}}\right) / \mathrm{FIM}_{\mathrm{Max}}}$ & Revised MRFS (MRFS-R) \\
\hline
\end{tabular}

functional status attainable. ${ }^{86-88}$ Lastly, by fixing max (BI or FIM) as the maximum score of activities of daily living measure used, rehabilitation indices become standardised which is important when comparing across studies, sites or time. We recommend that users of RIIs that contain the variable max (BI or FIM) clearly state in their publications which 'maximal score attainable' they used (ie, maximum score of functional measure or premorbid functional status).

It is also noteworthy that there may be trade-off relationships between RIIs with respect to certain independent predictors. Koh et $a l^{26}$ found that a shorter LOS and poorer prerehabilitation functional status was predictive of poorer REs, but longer LOS and better prerehabilitation functional status was predictive of poorer REy. The authors also demonstrated a trade-off relationship between REs and REy with respect to LOS and prerehabilitation functional status, and identified the ideal range of LOS and prerehabilitation functional status which optimised REs and REy.

Having the same RII with different synonyms is confusing and limits dissemination of results in the international research community, especially within the multidisciplinary field of rehabilitation. To standardise the terminology of RIIs with the same mathematical formula, we propose a harmonised nomenclature system for RIIs on the basis that the name for the RII should follow the name coined by the first author(s) to define it, and be logical and intuitive, as detailed in table 4 . While subject to international acceptance, we feel that our harmonised nomenclature system for RIIs is fairer to the authors who first named it and more easily understood.

A limitation in our study was the use of only one citation database for our literature search. However, we felt that this was sufficient as a high percentage of healthcare, medical and rehabilitation articles would be archived in this database. Another limitation of our qualitative systematic review was that it would underidentify predictors of RIIs compared to a quantitative one (ie, a meta-analysis) as the latter would have greater power to achieve statistical significance due to larger sample sizes from pooling of studies. Another limitation was that our literature search was limited to only articles in English due to the high cost of technical translations. Another limitation is the validity of how these rehabilitation indices were recorded. As the FIM and the Barthel index generate ordinal data, it should not be treated as interval numbers and factor analysis should be used to group related measures together. Factor analyses have consistently shown that the FIM comprises two separate factors (a motor and a cognitive factor), ${ }^{87}$ and Rasch analysis had suggested that FIM scores should use a transformation to convert ordinal data into interval data. $^{88} 89$ Thus, the raw ordinal scores should not be summed into a single total, and the above mathematical manipulations (subtraction or division) of rehabilitation indices (table 4) may not be valid. In addition, although FIM and BI have recognised floor/ceiling effects, ${ }^{89-93}$ only three studies specifically reported extremes of 
dependency predicting FIM efficiency (Gagnon et $a l^{57}$ $\mathrm{Yu}$ et $a \bar{l}^{59}$ and Turner-Strokes $e t a l^{63}$; table 3$)$, which may suggest reporting bias. However, we feel that it could be because most of the studies have either not reached extremes of dependency or authors may not have checked for extremes in the first place. For example, in Turner-Strokes et $a l$ s article, the study population was patients with severe acquired brain injury which ranged from the severely functionally impaired to those who recovered well. The literature search was also only conducted by one author (GCK) although the data extraction and analysis were verified by the other three authors, independently. We also acknowledge that our system of weighing the level of evidence for predictors of RIIs based on number of supporting articles was qualitative and arbitrary. Despite these study limitations, this systematic review is the first in rehabilitation literature to methodically review all RIIs available based on their common formula for calculation, assess the evidence for independent predictors of these RIIs applied over a wide range of medical conditions and study populations, and propose a nomenclature system to harmonise the names of RIIs across the rehabilitation discipline based on a rational first-named basis.

\section{CONCLUSIONS}

In conclusion, there are many RIIs reported in the literature and they include AFG, REs, REy, RREy and RREs, with REy having the most number of studies using it as an outcome measure and hence, having the strongest evidence for its predictors. Although the evidence for different predictors of RIIs varies according to the RII, medical condition and study population, there is good evidence that older age, lower prerehabilitation functional status and cognitive impairment are predictive of poorer AFG, REs and REy. A new nomenclature system is proposed to harmonise the names of RIIs based on a common mathematical formula and a firstnamed basis.

Acknowledgements The authors would like to thank the libraries of National University of Singapore and University of Western Ontario for support in article retrieval.

Contributors The literature search, initial study data extraction and tabulation of results were performed by GCK and $\mathrm{CHC}$, and verification of data extracted and results tabulated were subsequently performed by $\mathrm{CHC}, \mathrm{RP}$ and $\mathrm{AT}$ independently.

Funding Ministry of Health (Singapore) Health Services Research Competitive Research Grant Number HSRG/0006/2013.

\section{Competing interests None.}

Provenance and peer review Not commissioned; externally peer reviewed.

Data sharing statement No additional data are available.

Open Access This is an Open Access article distributed in accordance with the Creative Commons Attribution Non Commercial (CC BY-NC 3.0) license, which permits others to distribute, remix, adapt, build upon this work noncommercially, and license their derivative works on different terms, provided the original work is properly cited and the use is non-commercial. See: http:// creativecommons.org/licenses/by-nc/3.0/

\section{REFERENCES}

1. Heinemann AW, Roth EJ, Cichowski K, et al. Multivariate analysis of improvement and outcome following stroke rehabilitation. Arch Neurol 1987;44:1167-72.

2. Pronovost PJ, Miller M, Wachter RM. The GAAP in quality measurement and reporting. JAMA 2007;298:1800-2.

3. Hayward RA. Performance measurement in search of a path. $N$ Engl J Med 2007;356:951-3.

4. Liberati A, Altman DG, Tetzlaff J, et al. The PRISMA statement for reporting systematic reviews and meta-analyses of studies that evaluate healthcare interventions: explanation and elaboration. BMJ 2009;339:b2700.

5. Koh GC, Khoo HE, Wong ML, et al. The effects of problem-based learning during medical school on physician competency: a systematic review. CMAJ 2008;178:34-41.

6. Smits PB, Verbeek JH, De Buisonje CD. Problem based learning in continuing medical education: a review of controlled evaluation studies. BMJ 2002;324:153-6.

7. Heruti RJ, Lusky A, Barell V, et al. Cognitive status at admission: does it affect the rehabilitation outcome of elderly patients with hip fracture? Arch Phys Med Rehabil 1999;80:432-6.

8. Khan F, Turner-Stokes L, Stevermuer T, et al. Multiple sclerosis rehabilitation outcomes: analysis of a national casemix data set from Australia. Mult Scler 2009;15:869-75.

9. Rolland Y, Pillard F, Lauwers-Cances V, et al. Rehabilitation outcome of elderly patients with hip fracture and cognitive impairment. Disabil Rehabil 2004;26:425-31.

10. Hershkovitz A, Brill S. The association between patients' cognitive status and rehabilitation outcome in a geriatric day hospital. Disabil Rehabil 2007;29:333-7.

11. Leung AW, Cheng SK, Mak AK, et al. Functional gain in hemorrhagic stroke patients is predicted by functional level and cognitive abilities measured at hospital admission. NeuroRehabilitation 2010;27:351-8.

12. Zeilig G, Weingarden HP, Zwecker M, et al. Civilian spinal cord injuries due to terror explosions. Spinal Cord 2010;48:814-18.

13. Meiner Z, Sajin A, Schwartz I, et al. Rehabilitation outcomes of stroke patients treated with tissue plasminogen activator. PM $R$ 2010;2:698-702.

14. Shah S, Vanclay F, Cooper B. Efficiency, effectiveness, and duration of stroke rehabilitation. Stroke 1990;21:241-6.

15. Lin JH, Chang CM, Liu CK, et al. Efficiency and effectiveness of stroke rehabilitation after first stroke. J Formos Med Assoc 2000;99:483-90.

16. Heruti RJ, Lusky A, Dankner R, et al. Rehabilitation outcome of elderly patients after a first stroke: effect of cognitive status at admission on the functional outcome. Arch Phys Med Rehabil 2002;83:742-9.

17. Micieli G, Cavallini A, Quaglini S, et al. Guideline compliance improves stroke outcome: a preliminary study in 4 districts in the Italian region of Lombardia. Stroke 2002;33:1341-7.

18. Adunsky A, Lusky A, Arad M, et al. A comparative study of rehabilitation outcomes of elderly hip fracture patients: the advantage of a comprehensive orthogeriatric approach. J Gerontol A Biol Sci Med Sci 2003;58:542-7.

19. Shiri-Sharvit O, Arad M, Mizrahi EH, et al. The association between psychotropic medication use and functional outcome of elderly hip-fracture patients undergoing rehabilitation. Arch Phys Med Rehabil 2005;86:1389-93.

20. Hershkovitz A, Kalandariov Z, Hermush V, et al. Factors affecting short-term rehabilitation outcomes of disabled elderly patients with proximal hip fracture. Arch Phys Med Rehabil 2007;88:916-21.

21. Guerini F, Frisoni GB, Bellelli G, et al. Subcortical vascular lesions and functional recovery in older patients with gait disorders. Arch Gerontol Geriatr 2007;45:87-96.

22. Lieberman D, Friger M. Rehabilitation outcome following hip fracture surgery in elderly diabetics: a prospective cohort study of 224 patients. Disabil Rehabil 2007;29:339-45.

23. Luk JK, Chiu PK, Chu LW. Rehabilitation of older Chinese patients with different cognitive functions: how do they differ in outcome? Arch Phys Med Rehabil 2008;89:1714-19.

24. Denti L, Agosti M, Franceschini M. Outcome predictors of rehabilitation for first stroke in the elderly. Eur J Phys Rehabil Med 2008;44:3-11.

25. Di Monaco M, Schintu S, Dotta M, et al. Severity of unilateral spatial neglect is an independent predictor of functional outcome after acute inpatient rehabilitation in individuals with right hemispheric stroke. Arch Phys Med Rehabil 2011;92:1250-6.

26. Koh GC, Chen C, Cheong A, et al. Trade-offs between effectiveness and efficiency in stroke rehabilitation. Int J Stroke 2012;7:606-14.

27. Dakin L, Peel N. Effect of accelerometry on the functional mobility of older rehabilitation inpatients as measured by functional 
independence measure-locomotion (FIM) gain: a retrospective matched cohort study. J Nutr Health Aging 2011;15:382-6.

28. Chae J, Zorowitz RD, Johnston MV. Functional outcome of hemorrhagic and nonhemorrhagic stroke patients after in-patient rehabilitation. Am J Phys Med Rehabil 1996;75:177-82.

29. Huang ME, Cifu DX, Keyser-Marcus L. Functional outcome after brain tumor and acute stroke: a comparative analysis. Arch Phys Med Rehabil 1998;79:1386-90.

30. Juneja G, Czyrny JJ, Linn RT. Admission balance and outcomes of patients admitted for acute inpatient rehabilitation. Am J Phys Med Rehabil 1998;77:388-93.

31. O'Dell MW, Barr K, Spanier D, et al. Functional outcome of inpatient rehabilitation in persons with brain tumors. Arch Phys Med Rehabil 1998;79:1530-4.

32. Oden KE, Kevorkian CG, Levy JK. Rehabilitation of the post-cardiac surgery stroke patient: analysis of cognitive and functional assessment. Arch Phys Med Rehabil 1998;79:67-71.

33. Cifu DX, Huang ME, Kolakowsky-Hayner SA, et al. Age, outcome, and rehabilitation costs after paraplegia caused by traumatic injury of the thoracic spinal cord, conus medullaris, and cauda equina. $J$ Neurotrauma 1999;16:805-15.

34. Gillen R, Eberhardt TL, Tennen $\mathrm{H}$, et al. Screening for depression in stroke: relationship to rehabilitation efficiency. J Stroke Cerebrovasc Dis 1999;8:300-6.

35. Johns JS, Cifu DX, Keyser-Marcus L, et al. Impact of clinically significant heterotopic ossification on functional outcome after traumatic brain injury. J Head Trauma Rehabil 1999;14:269-76.

36. McKinley WO, Huang ME, Brunsvold KT. Neoplastic versus traumatic spinal cord injury: an outcome comparison after inpatient rehabilitation. Arch Phys Med Rehabil 1999;80:1253-7.

37. McKinley WO, Kolakowsky SA, Kreutzer JS. Substance abuse, violence, and outcome after traumatic spinal cord injury. Am J Phys Med Rehabil 1999:78:306-12.

38. McKinley WO, Seel RT, Hardman JT. Nontraumatic spinal cord injury: incidence, epidemiology, and functional outcome. Arch Phys Med Rehabil 1999:80:619-23.

39. Moorthi S, Schneider WN, Dombovy ML. Rehabilitation outcomes in encephalitis-a retrospective study 1990-1997. Brain Inj 1999;13:139-46.

40. Huang ME, Cifu DX, Keyser-Marcus L. Functional outcomes in patients with brain tumor after inpatient rehabilitation: comparison with traumatic brain injury. Am J Phys Med Rehabil 2000;79:327-35.

41. Adunsky A, Levenkron S, Fleissig Y, et al. In-hospital referral source and rehabilitation outcome of elderly stroke patients. Aging (Milano) 2001;13:430-6.

42. Gillen R, Tennen H, McKee TE, et al. Depressive symptoms and history of depression predict rehabilitation efficiency in stroke patients. Arch Phys Med Rehabil 2001;82:1645-9.

43. Lin $\mathrm{JH}$. Influence of admission functional status on functional gain and efficiency of rehabilitation in first time stroke patients. Kaohsiung $J$ Med Sci 2001;17:312-18.

44. Lin JH, Hsiao SF, Liu CK, et al. Rehabilitation fees, length of stay and efficiency for hospitalized stroke patients: a preliminary study based on function-related groups. Kaohsiung J Med Sci 2001;17:475-83.

45. Marciniak CM, Sliwa JA, Heinemann AW, et al. Functional outcomes of persons with brain tumors after inpatient rehabilitation. Arch Phys Med Rehabil 2001:82:457-63.

46. McKinley WO, Seel RT, Gadi RK, et al. Nontraumatic vs. traumatic spinal cord injury: a rehabilitation outcome comparison. Am J Phys Med Rehabil 2001;80:693-9; quiz 700, 16.

47. Patrick L, Knoefel F, Gaskowski P, et al. Medical comorbidity and rehabilitation efficiency in geriatric inpatients. J Am Geriatr Soc 2001:49:1471-7.

48. Ergeletzis D, Kevorkian CG, Rintala D. Rehabilitation of the older stroke patient: functional outcome and comparison with younger patients. Am J Phys Med Rehabil 2002:81:881-9.

49. McKinley WO, Tewksbury MA, Mujteba NM. Spinal stenosis vs traumatic spinal cord injury: a rehabilitation outcome comparison. J Spinal Cord Med 2002;25:28-32.

50. Murakami M, Inouye M. Stroke rehabilitation outcome study: a comparison of Japan with the United States. Am J Phys Med Rehabil 2002;81:279-82.

51. Roth EJ, Lovell L, Harvey RL, et al. Stroke rehabilitation: indwelling urinary catheters, enteral feeding tubes, and tracheostomies are associated with resource use and functional outcomes. Stroke 2002;33:1845-50.

52. Kevorkian CG, Kaldis T, Mahajan G, et al. Rehabilitation of postcardiac surgery stroke patients. Progress, outcomes, and comparisons with other stroke patients. Am J Phys Med Rehabil 2003;82:537-43.

53. Forrest GP. Inpatient rehabilitation of patients requiring hemodialysis. Arch Phys Med Rehabil 2004;85:51-3.
54. Lenze EJ, Munin MC, Dew MA, et al. Adverse effects of depression and cognitive impairment on rehabilitation participation and recovery from hip fracture. Int J Geriatr Psychiatry 2004;19:472-8.

55. Shah MK, Al-Adawi S, Dorvlo AS, et al. Functional outcomes following anoxic brain injury: a comparison with traumatic brain injury. Brain Inj 2004;18:111-17.

56. Forrest $\mathrm{G}$, Nagao M, lqbal $\mathrm{A}$, et al. Inpatient rehabilitation of patients requiring hemodialysis: improving efficiency of care. Arch Phys Med Rehabil 2005;86:1949-52.

57. Gagnon D, Nadeau S, Tam V. Clinical and administrative outcomes during publicly-funded inpatient stroke rehabilitation based on a case-mix group classification model. J Rehabil Med 2005;37:45-52.

58. Yu F, Richmond T. Factors affecting outpatient rehabilitation outcomes in elders. J Nurs Scholarsh 2005;37:229-36.

59. Yu F, Evans LK, Sullivan-Marx EM. Functional outcomes for older adults with cognitive impairment in a comprehensive outpatient rehabilitation facility. J Am Geriatr Soc 2005;53:1599-606.

60. Bottemiller KL, Bieber PL, Basford JR, et al. FIM score, FIM efficiency, and discharge disposition following inpatient stroke rehabilitation. Rehabil Nurs 2006:31:22-5.

61. Diamond PT, Conaway MR, Mody SH, et al. Influence of hemoglobin levels on inpatient rehabilitation outcomes after total knee arthroplasty. J Arthroplasty 2006;21:636-41.

62. Salter K, Jutai J, Hartley M, et al. Impact of early vs delayed admission to rehabilitation on functional outcomes in persons with stroke. J Rehabil Med 2006;38:113-17.

63. Turner-Stokes L, Paul S, Williams H. Efficiency of specialist rehabilitation in reducing dependency and costs of continuing care for adults with complex acquired brain injuries. $J$ Neurol Neurosurg Psychiatry 2006;77:634-9.

64. Vincent KR, Vincent HK, Lee LW, et al. Outcomes after inpatient rehabilitation of primary and revision total hip arthroplasty. Arch Phys Med Rehabil 2006;87:1026-32.

65. Vincent KR, Vincent HK, Lee LW, et al. Outcomes in total knee arthroplasty patients after inpatient rehabilitation: influence of age and gender. Am J Phys Med Rehabil 2006;85:482-9.

66. Vincent KR, Vincent HK, Lee LW, et al. Inpatient rehabilitation outcomes in primary and revision total knee arthroplasty patients. Clin Orthop Relat Res 2006:446:201-7.

67. Vincent HK, Alfano AP, Lee L, et al. Sex and age effects on outcomes of total hip arthroplasty after inpatient rehabilitation. Arch Phys Med Rehabil 2006;87:461-7.

68. Yokoyama O, Sakuma F, Itoh R, et al. Paraplegia after aortic aneurysm repair versus traumatic spinal cord injury: functional outcome, complications, and therapy intensity of inpatient rehabilitation. Arch Phys Med Rehabil 2006;87:1189-94.

69. $\mathrm{Ng}$ YS, Stein J, Ning M, et al. Comparison of clinical characteristics and functional outcomes of ischemic stroke in different vascular territories. Stroke 2007;38:2309-14.

70. Ng YS, Jung H, Tay SS, et al. Results from a prospective acute inpatient rehabilitation database: clinical characteristics and functional outcomes using the Functional Independence Measure. Ann Acad Med Singapore 2007;36:3-10.

71. Vincent HK, Weng JP, Vincent KR. Effect of obesity on inpatient rehabilitation outcomes after total hip arthroplasty. Obesity (Silver Spring) 2007;15:522-30.

72. Vincent HK, Vincent KR, Lee LW, et al. Effect of obesity on inpatient rehabilitation outcomes following total knee arthroplasty. Clin Rehabil 2007;21:182-90.

73. Kortebein P, Bopp MM, Granger CV, et al. Outcomes of inpatient rehabilitation for older adults with debility. Am J Phys Med 2008;87:118-25.

74. Ottenbacher KJ, Campbell J, Kuo YF, et al. Racial and ethnic differences in postacute rehabilitation outcomes after stroke in the United States. Stroke 2008;39:1514-19.

75. Rabadi MH, Rabadi FM, Edelstein L, et al. Cognitively impaired stroke patients do benefit from admission to an acute rehabilitation unit. Arch Phys Med Rehabil 2008;89:441-8.

76. Woo J, Chan SY, Sum MW, et al. In patient stroke rehabilitation efficiency: influence of organization of service delivery and staff numbers. BMC Health Serv Res 2008;8:86.

77. Tay SS, Ng YS, Lim PA. Functional outcomes of cancer patients in an inpatient rehabilitation setting. Ann Acad Med Singapore 2009;38:197-201.

78. Luk JK, Chan CF, Chan FH, et al. Rehabilitation outcomes of older Chinese patients with different cognitive function in a geriatric day hospital. Arch Gerontol Geriatr 2011:53:e144-8.

79. Gialanella B, Ferlucci C. Functional outcome after stroke in patients with aphasia and neglect: assessment by the motor and cognitive functional independence measure instrument. Cerebrovasc Dis 2010;30:440-7. 
80. Semel J, Gray JM, Ahn HJ, et al. Predictors of outcome following hip fracture rehabilitation. $P M R$ 2010;2:799-805.

81. Pellicane AJ, Wysocki NM, Mallinson TR, et al. Prevalence of 25-hydroxyvitamin $D$ deficiency in the acute inpatient rehabilitation population and its effect on function. Arch Phys Med Rehabil 2011:92:705-11.

82. Tian W, DeJong G, Horn SD, et al. Efficient rehabilitation care for joint replacement patients: skilled nursing facility or inpatient rehabilitation facility? Med Decis Making 2012;32:176-87.

83. Zwecker M, Levenkrohn S, Fleisig Y, et al. Mini-Mental State Examination, cognitive FIM instrument, and the Loewenstein Occupational Therapy Cognitive Assessment: relation to functional outcome of stroke patients. Arch Phys Med Rehabil 2002;83:342-5.

84. Toglia J, Fitzgerald KA, O'Dell MW, et al. The Mini-Mental State Examination and Montreal Cognitive Assessment in persons with mild subacute stroke: relationship to functional outcome. Arch Phys Med Rehabil 2011:92:792-8.

85. Press $\mathrm{Y}$, Grinshpun $\mathrm{Y}$, Berzak A, et al. The effect of co-morbidity on the rehabilitation process in elderly patients after hip fracture. Arch Gerontol Geriatr 2007;45:281-94.

86. Tangeman PT, Banaitis DA, Williams AK. Rehabilitation of chronic stroke patients: changes in functional performance. Arch Phys Med Rehabil 1990;71:876-80.
87. Werner RA, Kessler S. Effectiveness of an intensive outpatient rehabilitation program for postacute stroke patients. Am J Phys Med Rehabil 1996;75:114-20.

88. Wade DT, Collen FM, Robb GF, et al. Physiotherapy intervention late after stroke and mobility. BMJ 1992;304:609-13.

89. Hsueh IP, Lin JH, Jeng JS. Comparison of the psychometric characteristics of the functional independence measure, 5 item Barthel index, and 10 item Barthel index in patients with stroke. J Neurol Neurosur Ps 2002;73:188-90.

90. Brock KA, Goldie PA, Greenwood KM, et al. Evaluating the effectiveness of stroke rehabilitation: Choosing a discriminative measure. Archives of physical medicine and rehabilitation 2002;83:92-9.

91. Grey N, Kennedy P. The Functional Independence Measure - a Comparative-Study of Clinician and Self Ratings. Paraplegia 1993;31:457-61.

92. Coster WJ, Haley SM, Jette AM, et al. Measuring patient-reported outcomes after discharge from inpatient rehabilitation settings. ournal of Rehabilitation Medicine 2006;38:237-42.

93. Dromerick AW, Edwards DF, Diringer MN, et al. Sensitivity to changes in disability after stroke: A comparison of four scales useful in clinical trials. Journal of rehabilitation research and development 2003;40:1-8. 